Chapman University

Chapman University Digital Commons

Pharmacy Faculty Articles and Research

School of Pharmacy

$8-2006$

\title{
Synthesis of Lanthanum-Strontium Manganites by Oxalate-Precursor Co-Precipitation Methods in Solution and in Reverse Micellar Microemulsion
}

Vuk Uskoković

Chapman University, uskokovi@chapman.edu

Miha Drofenik

Jožef Štefan Institute

Follow this and additional works at: http://digitalcommons.chapman.edu/pharmacy_articles

Part of the Other Chemistry Commons, and the Physical Chemistry Commons

\section{Recommended Citation}

Uskoković, V., Drofenik, M., 2006. Synthesis of lanthanum-strontium manganites by oxalate-precursor co-precipitation methods in solution and in reverse micellar microemulsion. Journal of Magnetism and Magnetic Materials 303, 214-220. doi:10.1016/

j.jmmm.2005.06.034

This Article is brought to you for free and open access by the School of Pharmacy at Chapman University Digital Commons. It has been accepted for inclusion in Pharmacy Faculty Articles and Research by an authorized administrator of Chapman University Digital Commons. For more information, please contact laughtin@chapman.edu. 


\title{
Synthesis of Lanthanum-Strontium Manganites by Oxalate-Precursor Co- Precipitation Methods in Solution and in Reverse Micellar Microemulsion
}

\author{
Comments \\ NOTICE: this is the author's version of a work that was accepted for publication in Journal of Magnetism and \\ Magnetic Materials. Changes resulting from the publishing process, such as peer review, editing, corrections, \\ structural formatting, and other quality control mechanisms may not be reflected in this document. Changes \\ may have been made to this work since it was submitted for publication. A definitive version was subsequently \\ published in Journal of Magnetism and Magnetic Materials, volume 303, in 2006. DOI: 10.1016/ \\ j.jmmm.2005.06.034
}

The Creative Commons license below applies only to this version of the article.

\section{Creative Commons License}

\section{(c) $\mathbb{\theta} \Theta \Theta$}

This work is licensed under a Creative Commons Attribution-Noncommercial-No Derivative Works 4.0 License.

\section{Copyright}

Elsevier 


\title{
Synthesis of Lanthanum-Strontium Manganites by Oxalate-Precursor Co- Precipitation Methods in Solution and in Reverse Micellar Microemulsion
}

\author{
Vuk Uskoković ${ }^{1}$, Miha Drofenik ${ }^{1,2}$ \\ ${ }^{1} \gg$ Jožef Stefan « Institute, Jamova 39, 1000 Ljubljana, Slovenia \\ ${ }^{2}$ Faculty of Chemistry and Chemical Engineering, Smetanova 17, 2000 Maribor, Slovenia
}

Corresponding author: vuk.uskokovic@ijs.si

Keywords: Co-precipitation, Manganite, Microemulsion, Nanosize, Reverse Micelle

\begin{abstract}
Nanostructured lanthanum-strontium manganites were synthesized using two different co-precipitation approaches, one in bulk solution, and the other in reverse micelles of CTAB/1-hexanol/water microemulsion. In both cases, precursor cations were precipitated by using oxalic acid. The properties of the materials synthesized by using these two methods were compared in order to reveal potential advantages of the microemulsion-assisted approach. The influence of the annealing conditions on the properties of synthesized manganites was investigated by using X-ray diffraction, transmission electron microscopy, differential thermal analysis, thermogravimetric analysis and magnetic measurements.
\end{abstract}

\section{Introduction}

Preparation of materials within reverse micelles ${ }^{1-3}$ belongs to the family of wet synthesis procedures, known of a number of advantages comparing to the traditional high-temperature solid-state processing methods, such as excellent control of the final powders' stoichiometries with possibilities of obtaining homogeneity and mixing on atomic scale, narrow particle sizes distribution, negligible contamination of the product during the homogenization of the starting compounds, low energy consumption, low aging times and simple equipment. Parameters of reverse micellar synthesis of nanoparticles, usually manipulated and controlled in the courses of variety of design procedures, include: water-to-surfactant ${ }^{4,5}$ and surfactant-to-co-surfactant ${ }^{6}$ molar ratios, ionic strength ${ }^{7,8}$, temperature ${ }^{9}$, aging time ${ }^{10,11}$, etc. However, due to the signs of frequent uniqueness and significant narrowness of limiting conditions in the processes of reverse micellar preparation of materials, deep questions have recently been raised upon the problem of justifying the generalizations of relationships between particular parent microemulsion systems and the obtained particles ${ }^{12}$.

It is known that catalytic activity of LaSr-manganites largely depends on the method of its synthesis ${ }^{13}$. Although the methods for the preparation of $\mathrm{LaMnO}_{3}$ in reverse micelles were already reported in the literature ${ }^{14-16}$, the only synthesis of $\mathrm{LaSrMnO}_{3}$ or of any mixed lanthanum manganite within reverse micelles, published elsewhere is our previous work ${ }^{17}$ concerning co-precipitation preparation of $\mathrm{La}_{0.67} \mathrm{Sr}_{0.33} \mathrm{MnO}_{3+\delta}$ in CTAB/1-butanol/1-hexanol/water microemulsion by using tetramethylammonium hydroxide as an alkali precipitating agent. Synthesis of different perovskite mixed metal oxides by using oxalate precursors (including $\left.\mathrm{La}_{1-\mathrm{x}} \mathrm{Sr}_{\mathrm{x}} \mathrm{MnO}_{3}\right)^{18}$ has been noticed elsewhere, and is largely excepted as a method which produces uniform cation distribution $^{19,20}$. 


\section{Experimental}

Two different wet, oxalate-precursor co-precipitation approaches to the synthesis of LaSr-manganites - one in bulk solution and the other in the reverse micelles of $\mathrm{CTAB} / 1$-hexanol/water microemulsion, were performed and investigated within the work presented here. In both cases, the composition $\mathrm{La}_{0.67} \mathrm{Sr}_{0.33} \mathrm{MnO}_{3+\delta}$ was desired as the final product. The following chemicals were used in the course of the syntheses procedures:

The co-precipitation synthesis in bulk solution proceeded as follows. The $6 \mathrm{ml}$ of aqueous solution comprised the molar ratio of precursor cations $\mathrm{Mn}: \mathrm{La}: \mathrm{Sr}=4.6: 2.2$ : 1. $\mathrm{MnCl}_{2}$ (>99\%, Merck-Alkaloid), $\mathrm{La}\left(\mathrm{NO}_{3}\right)_{3}\left(99.9 \%\right.$, Alfa Aesar) and $\operatorname{Sr}\left(\mathrm{NO}_{3}\right)_{2}(>99 \%$, Kemika) were used as precursor salts. $\mathrm{MnCl}_{2}$ was preferred over $\mathrm{Mn}\left(\mathrm{NO}_{3}\right)_{2}$ due to easy oxidation of $\mathrm{Mn}^{2+}$ by dissolved oxygen in the aqueous nitrate solution. However, $\mathrm{Mn}^{2+}$ ions ought to be added in an amount that surpasses the stoichiometric amount due to the formation of $\mathrm{Mn}^{2+}$ - complex compounds ${ }^{20}$ with nitrate ions, that are stable in the presence of an acidic precipitating agent. Different amounts of pure ethanol (99.8\%, Carlo Erba) were then added into the prepared solution. Saturated aqueous solution of oxalic acid ( $>99.5 \%$, Alkaloid) was then added into the hydro-alcoholic solution so that the volume of the acid was 1.1 times the volume of the precursor solution. The colloid solutions were aged for $3 \mathrm{~h}$ at room temperature. Subsequently, the samples were repeatedly sedimented by performing centrifugation, and washed with ethanol - water (1:1) mixture, whereas the yielded powder was then dried at $80{ }^{\circ} \mathrm{C}$. The dried powders were then calcined in air at different temperatures and for different times.

The co-precipitation method of synthesis by using reverse micellar microemulsion was proceeding as follows. Two microemulsions with the identical CTAB (>99\%, Alfa Aesar) : 1-hexanol (>98\%, Merck-Schuchardt) : $\mathrm{H}_{2} \mathrm{O}=29.7$ : 55.1 : 15.2 weight ratios, were prepared, whereby in place of the aqueous phase, the first one carried aqueous solution of $\mathrm{MnCl}_{2}, \mathrm{La}\left(\mathrm{NO}_{3}\right)_{3}$ and $\mathrm{Sr}\left(\mathrm{NO}_{3}\right)_{2}$ with resulting cation concentration of $0.5 \mathrm{M}$ and molar ratio of $\mathrm{Mn}^{2+}: \mathrm{La}^{3+}: \mathrm{Sr}^{2+}=5: 2: 1$, whereas the second one comprised $0.84-\mathrm{M}$ aqueous solution of oxalic acid, which served as the precipitation agent. The weight ratio between the precursor and the precipitating microemulsion was set to 1.5. The two microemulsions were mixed and aged for $3 \mathrm{~h}$ at room temperature. The resulting oxalate precipitate, finely and uniformly dispersed within the resulting microemulsion, was then separated by centrifugation and repeatedly washed with $0.06-\mathrm{M}$ solution of oxalic acid in ethanol. The powder was then dried at $70{ }^{\circ} \mathrm{C}$ in air, and subsequently calcined under various annealing conditions.

The as-dried and subsequently calcined powders were analyzed by using TEM (JEOL JEM-2000FX), DSC and TGA measurements (Mettler-Toledo STAR System), room-temperature magnetic measurements (Manics DSM10 magnetometer), temperaturedependent magnetic measurements and X-ray diffraction analysis (D4 Endeavor diffractometer). Room-temperature measurements of the saturation magnetization were performed in the external field range from 0.84 to $1.06 \mathrm{~T}$. Average particle sizes were estimated by using Debye-Scherrer's equation. DSC and TGA measurements were performed in air up to $1200{ }^{\circ} \mathrm{C}$, with heating rates of $10{ }^{\circ} \mathrm{C} / \mathrm{min}$.

\section{Results and discussion}

On Figs. 1 and 2, XRD diagrams of the sample synthesized in bulk conditions, 
calcined at different temperatures for $2 \mathrm{~h}$ (Fig. 1) and at $700{ }^{\circ} \mathrm{C}$ for $2-24 \mathrm{~h}$ (Fig. 2), are shown. The formation of perovskite phase begins at between 500 and $700{ }^{\circ} \mathrm{C}$ (Fig. 1). During the heating at $700{ }^{\circ} \mathrm{C}$, the crystallization and grain growth processes were completed after between 2 and $3 \mathrm{~h}$ of the annealing time (Fig.2). The average particle size of the samples calcined for 3 or more hours is $11 \mathrm{~nm}$, according to Debye-Scherrer's equation. The samples calcined at $900{ }^{\circ} \mathrm{C}$ and $1100{ }^{\circ} \mathrm{C}$ were according to this account having average particle sizes of 13 and $27 \mathrm{~nm}$, respectively.

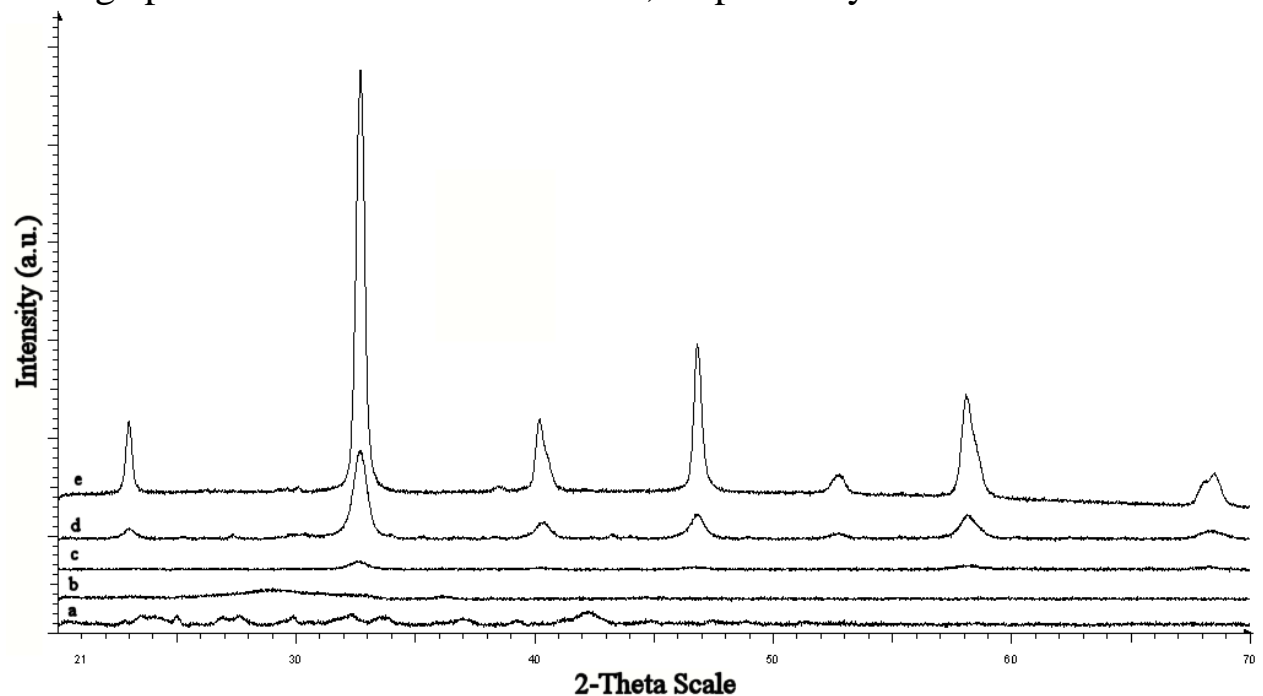

Fig. 1. XRD diagrams of the sample synthesized in bulk conditions. As-dried powder is denoted with a, whereby the samples calcined at 500, 700, 900 and $1100{ }^{\circ} \mathrm{C}$ for $2 \mathrm{~h}$ are denoted with b, c, d and e, respectively.

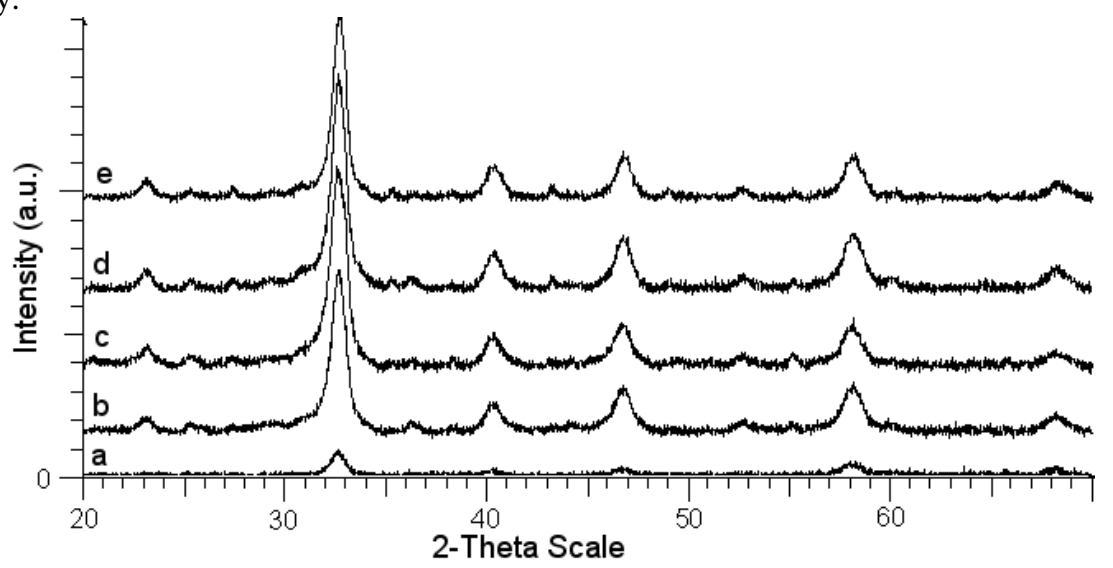

Fig. 2. XRD diagrams of the sample synthesized in bulk conditions and calcined at $700{ }^{\circ} \mathrm{C}$ for $2 \mathrm{~h} \mathrm{(a),} 3 \mathrm{~h}$ (b), $5 \mathrm{~h} \mathrm{(c),} 10 \mathrm{~h} \mathrm{(d)}$ and $24 \mathrm{~h}(\mathrm{e})$. 


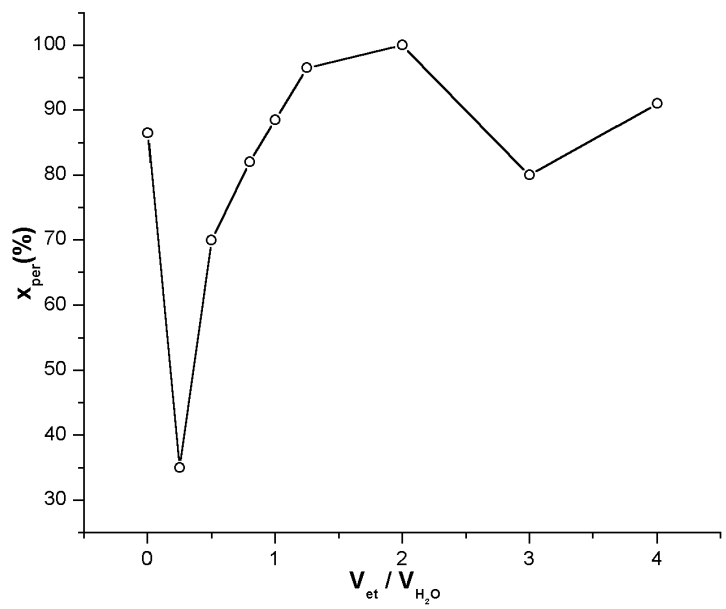

Fig. 3. XRD-determined weight ratio of perovskite manganite phase in the bulk-synthesized samples vs. ethanol-to-water volume ratio.

The dependence of the weight ratio of the obtained perovskite manganite phase within the synthesized samples vs. volume ratio of ethanol-to-water, is presented in Fig. 3. The optimal volume ratio of ethanol to water for the used initial concentrations and proportions of precursor salts, was found to be 2 , in which case, the perovskite phase was the only detected phase comprising the calcined samples. It is worth noting that for the samples represented by two end points in Fig. 3, $\mathrm{Mn}_{3} \mathrm{O}_{4}$ is gained as the only secondary phase, whereas in all the other cases $\mathrm{La}_{2} \mathrm{O}_{3}$ was detected as the only present crystalline secondary phase.

The samples calcined at $1100{ }^{\circ} \mathrm{C}$ were suspensed in water $(10 \mathrm{mg}$ in $20 \mathrm{ml}$ of water); $\mathrm{pH}$ value was 5.7 for the sample synthesized in microemulsion and 6.5 for the sample synthesized in bulk conditions, which was, due to the fact that amorphous $\mathrm{SrO}$ readily slakes with water yielding a crystalline hydrated hydroxide behaving as a strong base, a clear indication that $\mathrm{Sr}$ ions were not present in form of oxides separate from manganite phase. 


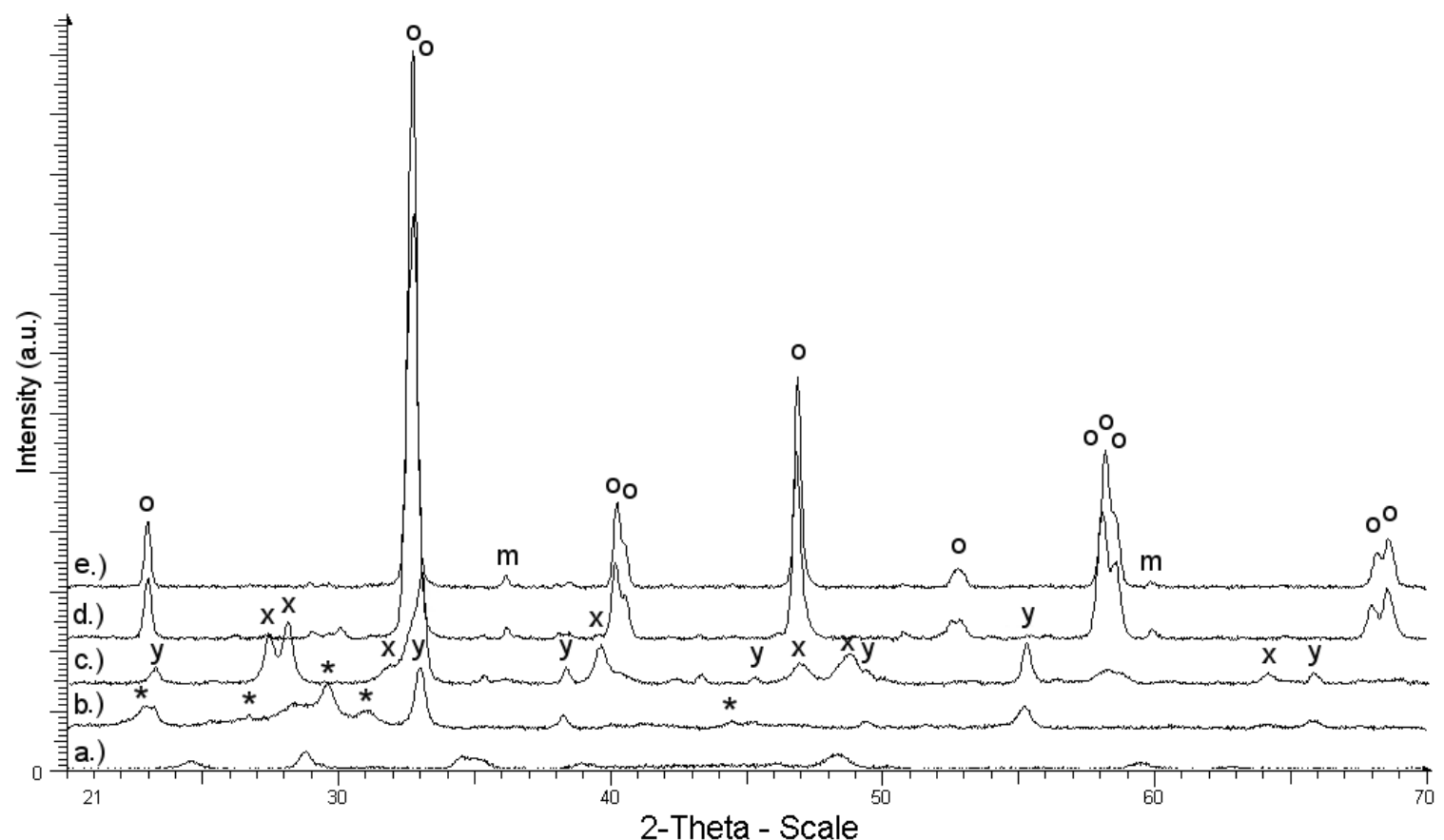

Fig. 4. XRD diagrams of the sample synthesized in reverse micelles. As-dried powder is denoted with a, whereby the samples calcined at $600,800,1000$ and $1100{ }^{\circ} \mathrm{C}$ for $2 \mathrm{~h}$ are denoted with b, c, d and e, respectively. o stands for perovskite $\mathrm{La}_{0.67} \mathrm{Sr}_{0.33} \mathrm{MnO}_{3}$; m stands for $\mathrm{Mn}_{3} \mathrm{O}_{4}$; x stands for $\mathrm{La}_{2} \mathrm{SrO}_{\mathrm{x}}$; y stands for cubic $\mathrm{Mn}_{2} \mathrm{O}_{3}$; * stands for tetragonal $\mathrm{La}_{2} \mathrm{O}_{2} \mathrm{CO}_{3}$.

From XRD diagram of the sample synthesized in microemulsion and calcined at different temperatures, presented in Fig. 4, it might be seen that precursor oxalates (and/or carbonates) comprising the as-dried powder transform to $\mathrm{La}_{2} \mathrm{O}_{2} \mathrm{CO}_{3}$ and $\mathrm{Mn}_{2} \mathrm{O}_{3}$ after heating at $600{ }^{\circ} \mathrm{C}$ for $2 \mathrm{~h}$, and possibly to less crystalline SrO, which was not identified by using XRD. Annealing of the as-dried powder in air at $700{ }^{\circ} \mathrm{C}$ for $10 \mathrm{~h}$ did not significantly change XRD pattern (not shown herein), still comprising $\mathrm{Mn}_{2} \mathrm{O}_{3}$ and $\mathrm{La}_{2} \mathrm{O}_{2} \mathrm{CO}_{3}$ diffraction peaks, which suggests that relatively high temperatures are necessary condition for the formation of manganite phase within microemulsion-assisted procedure of the synthesis as presented herein. After heating at $800{ }^{\circ} \mathrm{C}$ for $2 \mathrm{~h}, \mathrm{LaO}_{2} \mathrm{CO}_{3}$ and $\mathrm{SrO}$ transform to $\mathrm{La}_{2} \mathrm{SrO}_{\mathrm{x}}$, which subsequently, at higher calcination temperatures, reacts with $\mathrm{Mn}_{2} \mathrm{O}_{3}$ giving $\mathrm{LaSr}$-manganite with a slight amount of secondary $\mathrm{Mn}_{3} \mathrm{O}_{4}$ secondary phase. The samples calcined at $1000{ }^{\circ} \mathrm{C}$ and $1100{ }^{\circ} \mathrm{C}$ have average particle size of $23 \mathrm{~nm}$, according to Debye-Scherrer's equation. 


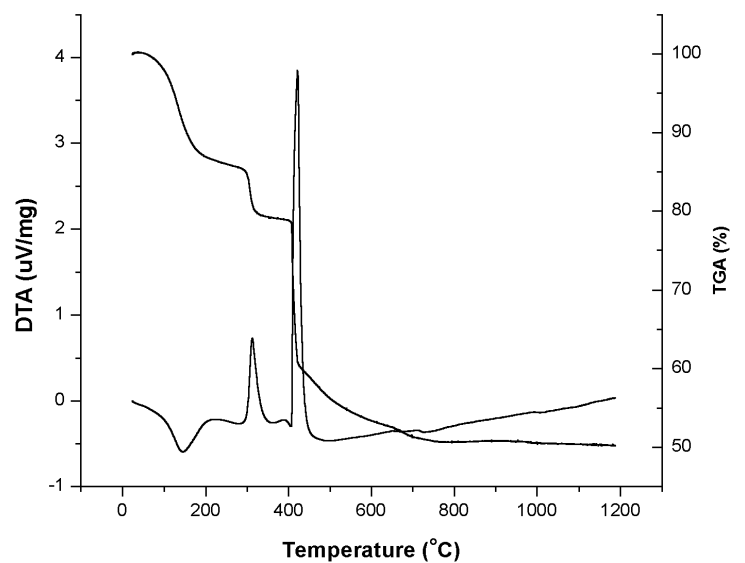

a.)

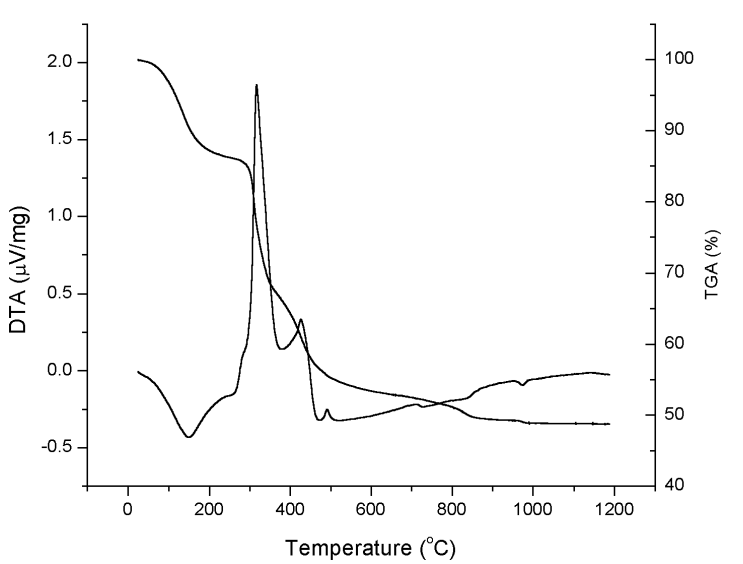

b.)

Fig. 5. DTA and TGA diagrams of the heating of the as-dried powders, synthesized under bulk conditions (a) and in microemulsion (b).

DTA and TGA diagrams of the heating of the as-dried powders, one synthesized in bulk conditions and the other in reverse micellar microemulsion, are shown in Fig. 5. Stoichiometric calculations have shown that $34 \%$ weight loss is expected during the process of decomposition of oxalate precursors (with account to the stoichiometric, noncomplete precipitation of $\mathrm{Mn}^{2+}$ ions) into $\mathrm{La}_{0.67} \mathrm{Sr}_{0.33} \mathrm{MnO}_{3}$, which is in accordance with experimental results. From the TGA results, water loss might be approximated to $~ 15 \%$ and the rest $\sim 35 \%$ belongs to the decomposition of oxalates. The endothermic peak at $150{ }^{\circ} \mathrm{C}$ derives from thermal dehydration of the oxalate precursors. Two more major exothermic peaks might be noticed at bulk-synthesized sample, with maximums at the temperatures of $312.3^{\circ} \mathrm{C}$ (typical for the wet approaches to the La-manganite synthesis ${ }^{21}$ ) and $421.6{ }^{\circ} \mathrm{C}$, whereby the sample synthesized within microemulsion exhibits the same two peaks slightly moved to higher temperatures: one at $316.8{ }^{\circ} \mathrm{C}$, and the second at $426.3^{\circ} \mathrm{C}$, whereby the third exothermic peak is present with maximum at $491.1^{\circ} \mathrm{C}$. The exothermic peak at $\sim 315^{\circ} \mathrm{C}$ is attributed to the thermal decomposition of $\mathrm{C}-\mathrm{H}$ and $\mathrm{C}-\mathrm{C}$ bonds of oxalate precursors ${ }^{22}$ and to the subsequent formation of oxycarbonate intermediate. Lanthanum oxalate is known to lose all of its bound water up to the temperature of $225{ }^{\circ} \mathrm{C}$, at $400{ }^{\circ} \mathrm{C}$ exothermally transforms to carbonate, then endothermally to oxycarbonate, and at $710{ }^{\circ} \mathrm{C}$ to oxide ${ }^{23}$. Strontium oxalate is known to endothermally release all bounded water up to $250{ }^{\circ} \mathrm{C}$, to exothermally transforms to strontium carbonate at between 420 and $590{ }^{\circ} \mathrm{C}$, whereby carbonate transforms endothermally to oxide ${ }^{24}$ at between $770{ }^{\circ} \mathrm{C}$ and $1020{ }^{\circ} \mathrm{C}$. Small endothermic peaks observed at $\mathrm{T}>700{ }^{\circ} \mathrm{C}$ might thus belong to the gradual incorporation of $\mathrm{Sr}$ ions into already formed manganite perovskite lattice. The minor weight loss step (starting at $700{ }^{\circ} \mathrm{C}$ ) in case of the microemulsion-assisted synthesized sample might as well occur due to the emission of carbon dioxide, since $\mathrm{La}_{2} \mathrm{O}_{2} \mathrm{CO}_{3}$ (that later transforms to perovskite oxide) was detected in the sample after heating at $800{ }^{\circ} \mathrm{C}$ (Fig. 4). 


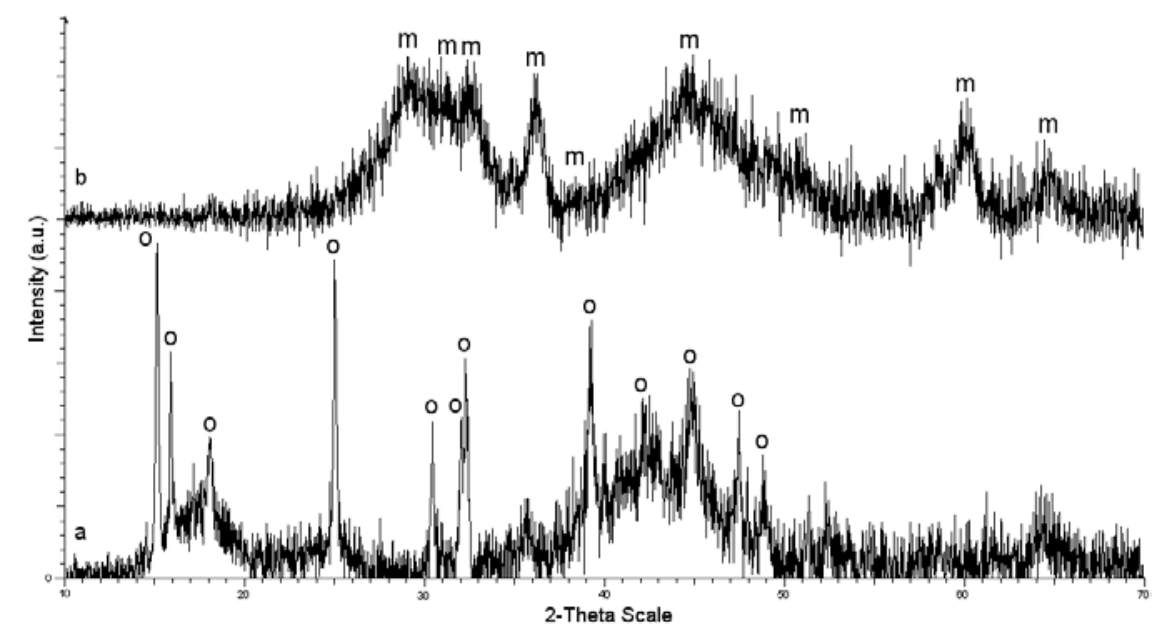

Fig. 6. XRD diagrams of the bulk-synthesized sample quenched up to $350{ }^{\circ} \mathrm{C}$ (a) and $470{ }^{\circ} \mathrm{C}$ (b) with the heating rate of $10{ }^{\circ} \mathrm{C} / \mathrm{min}$. o stands for cubic $\alpha-\mathrm{MnC}_{2} \mathrm{O}_{4}$, whereas $\mathrm{m}$ denotes cubic $\mathrm{Mn}_{3} \mathrm{O}_{4}$.

XRD diagrams of the bulk-synthesized powder heated up to temperatures corresponding to the end-points of two of the largest common exothermic phase transitions observed within the DSC measurements, are shown in Fig. 6. All diffraction peaks of the sample quenched to $350{ }^{\circ} \mathrm{C}$ correspond to cubic $\alpha-\mathrm{MnC}_{2} \mathrm{O}_{4}$, whereby all the peaks of the sample quenched at $470{ }^{\circ} \mathrm{C}$ correspond to cubic $\mathrm{Mn}_{3} \mathrm{O}_{4}$. However, the formation of perovskite phase might be noticed at the same XRD pattern. Therefore, the first exothermic peak on DSC diagram corresponds to the transformation of La and $\mathrm{Sr}$ precursors to amorphous oxycarbonates, whereby the second peak corresponds to the transition of Mn-oxalate to $\mathrm{Mn}_{3} \mathrm{O}_{4}$, followed by the gradual formation of perovskite manganite. Although thermal decomposition of hydrous manganese oxalate in air leads normally to an exothermic (in the temperature range $\left.230-330{ }^{\circ} \mathrm{C}\right)^{25}$ formation of $\mathrm{MnO}_{2}$, it is known that different oxalate hydrate stoichiometries and different environments can result in the formation of different manganese oxide products ${ }^{26}$.

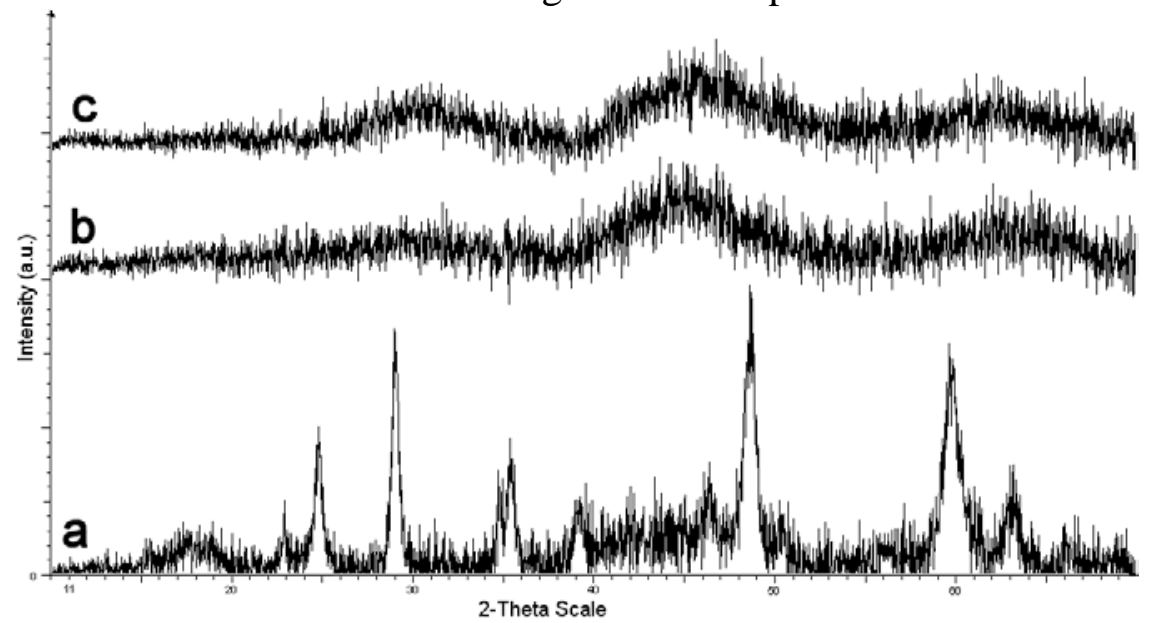

Fig. 7. XRD diagrams of the samples synthesized in microemulsion and quenched up to $370{ }^{\circ} \mathrm{C}$ (a), $460{ }^{\circ} \mathrm{C}$ (b) and $500{ }^{\circ} \mathrm{C}$ with the heating rate of $10^{\circ} \mathrm{C} / \mathrm{min}$.

In case of the microemulsion synthesis, after the first exothermic DSC peak at 317 ${ }^{\circ} \mathrm{C}$ no major changes in the XRD pattern were detected, whereas a gradual formation of manganese oxide phase through a transient amorphous phase is obvious to occur during 
the continual heating to both $420{ }^{\circ} \mathrm{C}$ and up to $500{ }^{\circ} \mathrm{C}$ (Fig. 7). Therefore, the first, endothermic DSC peak corresponds to the water loss, second, endothermic one to the phase transition in amorphous state, whereby the third peak corresponds to the transition of the crystalline phase comprising as-dried powder into manganese oxide phase, which subsequently reacts with $\mathrm{LaSrO}_{\mathrm{x}}$, yielding as a result, after sufficient thermal treatment, the manganite phase (Fig. 4).

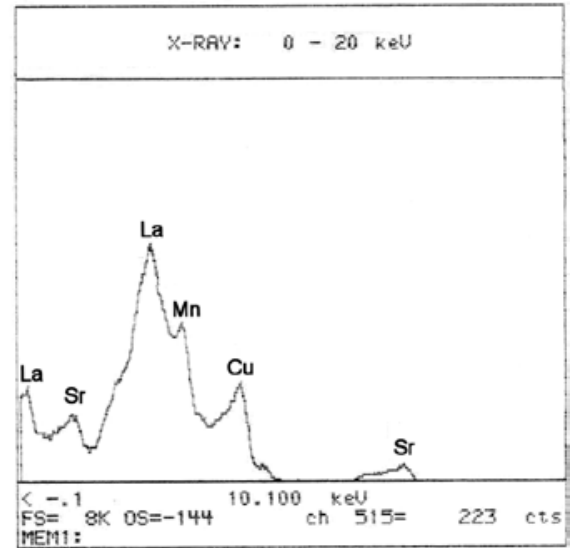

a.)

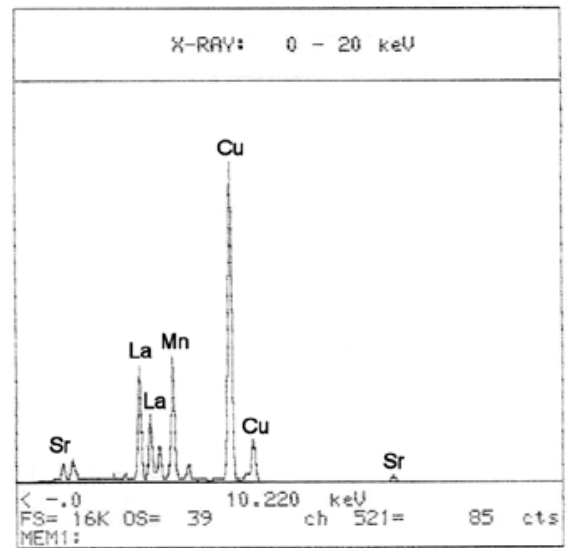

b.)

Fig. 8. EDS diagrams of the samples synthesized in bulk conditions (a) and within reverse micelles (b), calcined at $1100{ }^{\circ} \mathrm{C}$.

From the presented EDS spectra (Fig. 8) of the samples synthesized both in bulk conditions and within reverse micelles, and calcined at $1100{ }^{\circ} \mathrm{C}$, it is obvious that all three of the desired cations were constituent within the obtained products. Origin of the $\mathrm{Cu}$ peaks belongs to the copper grid used as the powder carrier within the TEM measurements.

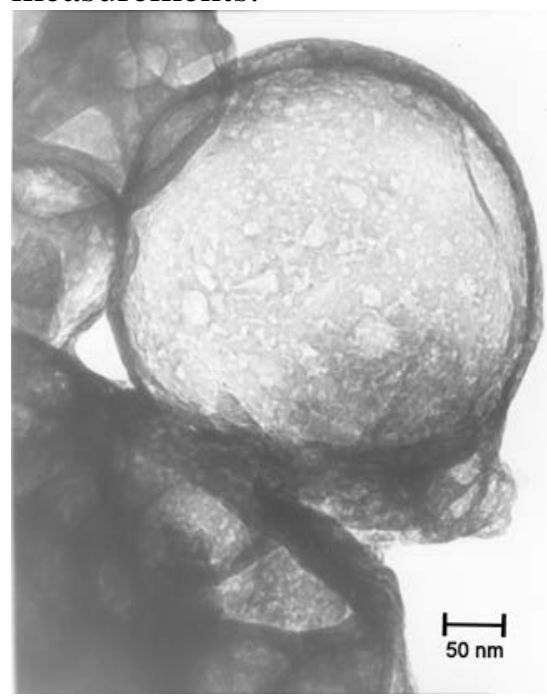

a.)

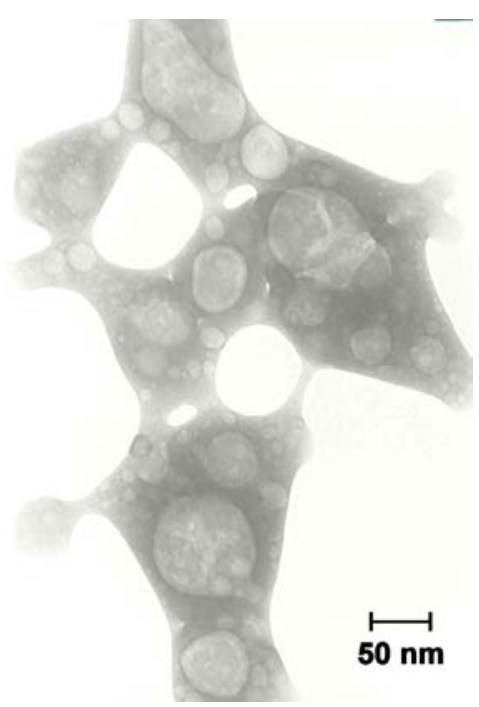

b.)

Fig 9. TEM images of the as-dried powders synthesized in bulk conditions (a) and in microemulsion (b). 


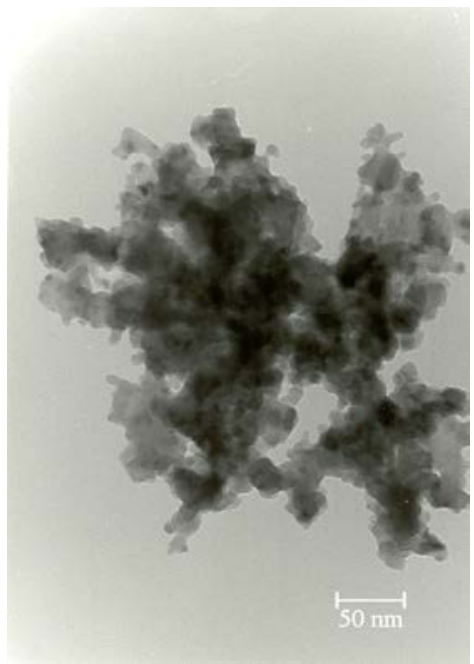

a.)

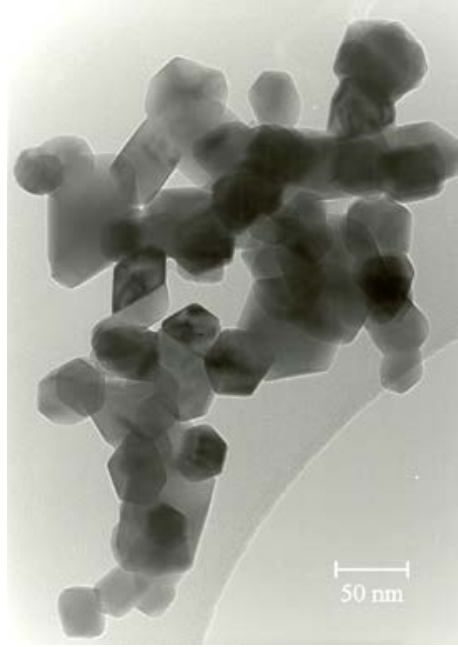

b.)

Fig. 10. TEM images of the samples synthesized in bulk conditions and calcined at $700{ }^{\circ} \mathrm{C}$ (a) and $1100{ }^{\circ} \mathrm{C}$ (b) for $2 \mathrm{~h}$.

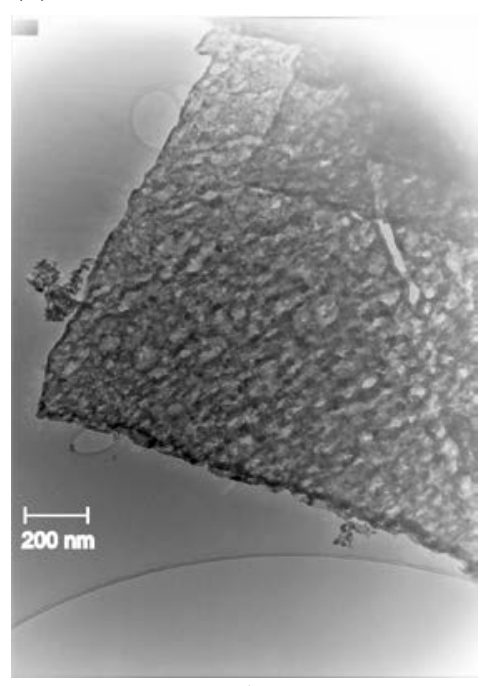

a.)

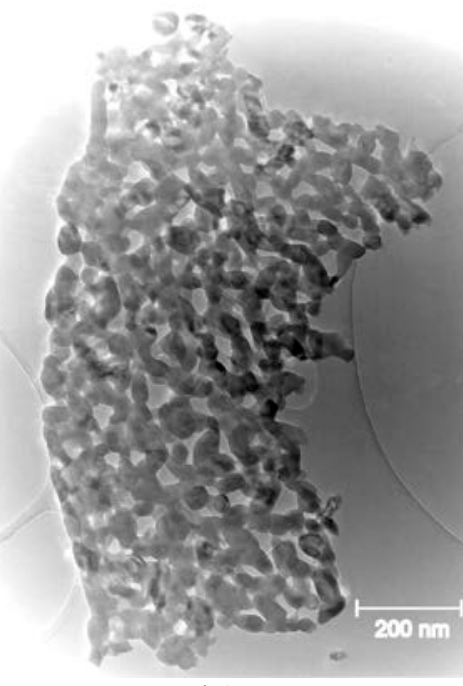

b.)

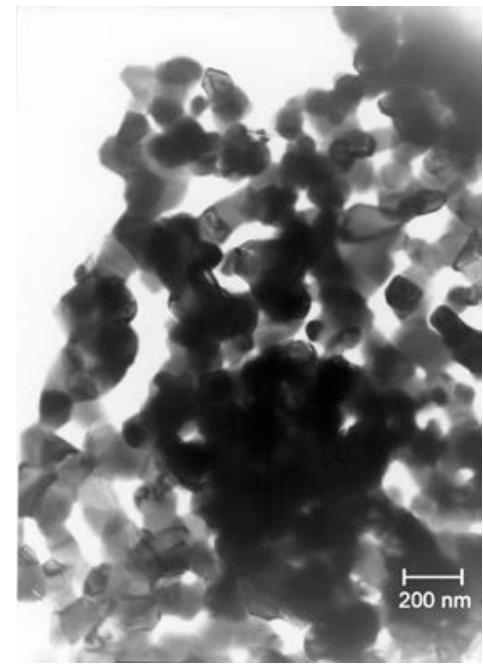

c.)

Fig. 11a,b,c. TEM images of the sample synthesized in bulk conditions and calcined at $700{ }^{\circ} \mathrm{C}$ for $3 \mathrm{~h}(\mathrm{a}, \mathrm{b})$ and of the sample synthesized in microemulsion and calcined at $1100{ }^{\circ} \mathrm{C}$ for $2 \mathrm{~h}$ (c).

TEM micrographs of some of the synthesized samples are presented in Figs. 9-11. Comparison of Fig.9a and Fig. 9b leads to the conclusion that much restricted growth processes in the precipitation of oxalate precursors occurred in the case of reverse micellar synthesis, as compared to the bulk case. Almost completely amorphous structure of the sample synthesized in bulk conditions and calcined at $700{ }^{\circ} \mathrm{C}$ for $2 \mathrm{~h}$, is presented in Fig. 10a, whereby crystalline nano-sized particles (in the range of $20-50 \mathrm{~nm}$ ) of the sample synthesized in bulk conditions and calcined at $1100{ }^{\circ} \mathrm{C}$ for $2 \mathrm{~h}$, are presented in Fig. 10b. Uniform nano-sized particles of the sample synthesized in bulk conditions and calcined at $700{ }^{\circ} \mathrm{C}$ for $3 \mathrm{~h}$ are presented in Figs. 11a and 11b, whereby low polydispersity of the sample synthesized in microemulsion and calcined at $1100{ }^{\circ} \mathrm{C}$ for $2 \mathrm{~h}$, might be noticed from Fig. 11c. 


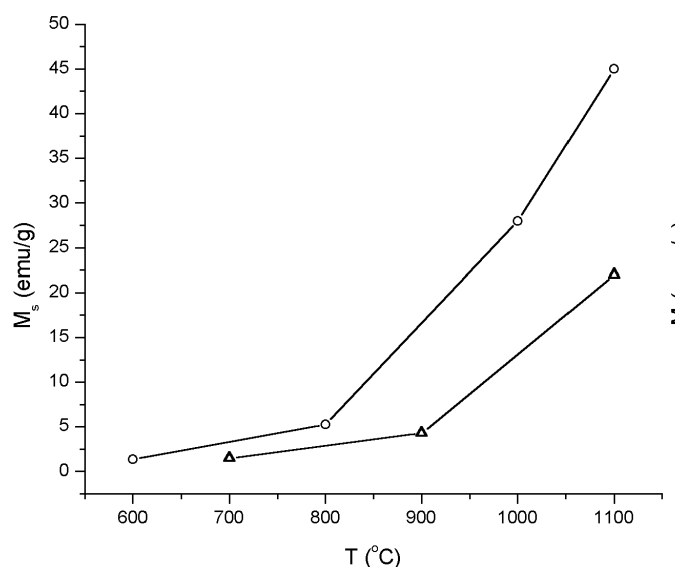

a.)

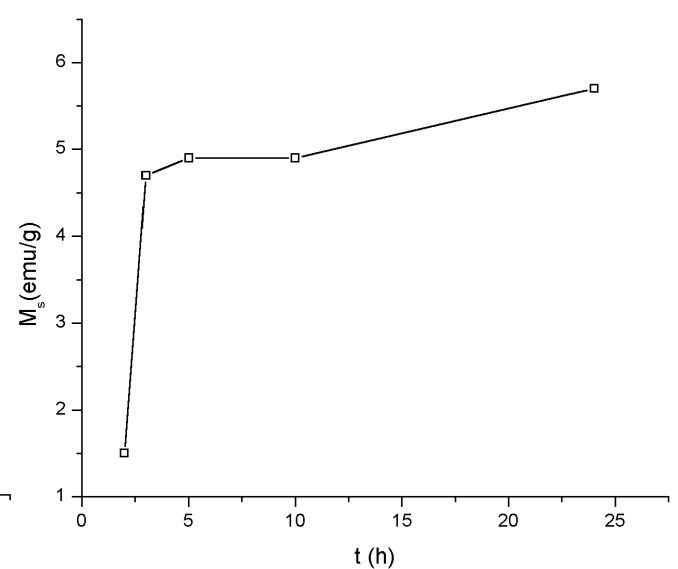

b.)

Fig. 12. Dependency of saturation magnetization on the calcination temperature for the samples synthesized in bulk conditions (- $\Delta-$ ) and in microemulsion (-o-) (a) and the dependence of the saturation magnetization on the calcination time for the sample synthesized in bulk conditions and calcined in air at $700{ }^{\circ} \mathrm{C}$.

The increase in saturation magnetization with an increase in calcination temperature, for the samples prepared by using both synthesis routes, is evident from the Fig. 12a. The magnetization of the bulk-synthesized sample calcined at $1100{ }^{\circ} \mathrm{C}$ for $2 \mathrm{~h}$ is twice smaller comparing to the microemulsion-assisted synthesized sample calcined at the same conditions. The magnetization of the sample synthesized in reverse micelles and calcined at $800{ }^{\circ} \mathrm{C}$ derives from the small amount of perovskite manganite phase, the sign of which is visible on the corresponding XRD diagram (Fig. 4c). At $800{ }^{\circ} \mathrm{C}$, the perovskite phase had obviously already started forming in case of the reverse micelle synthesized sample. From Fig. 12b, a large increase in magnetization value between the samples synthesized in bulk conditions and calcined at $700{ }^{\circ} \mathrm{C}$ for 2 and $3 \mathrm{~h}$, respectively, has been noticed, after which magnetization slowly increases when the calcination time is prolonged from $3-24 \mathrm{~h}$. The magnetization increase in this case goes together with an increase in crystallinity as is obvious from Fig. 2.

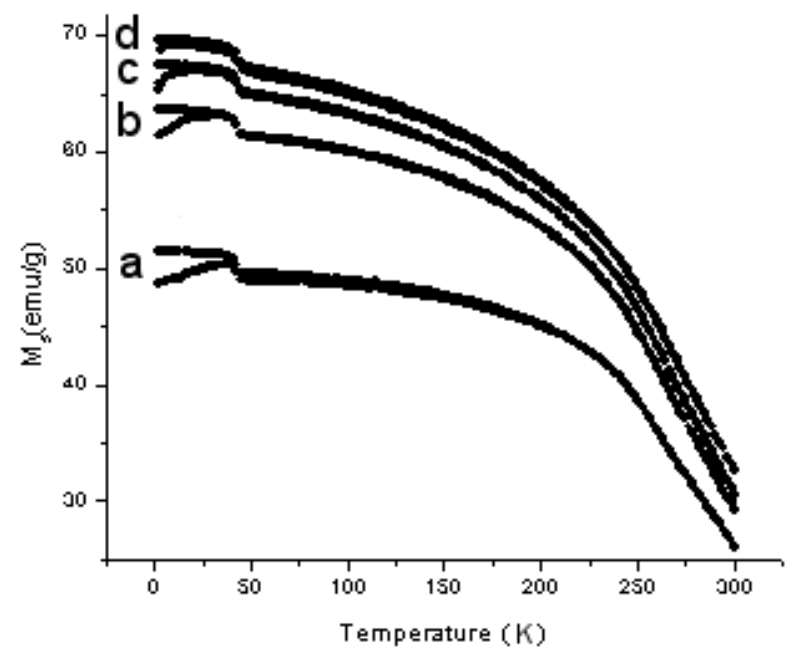

Fig. 13. Dependence of saturation magnetization on the measurement temperature for the sample synthesized in microemulsion and calcined at $1000^{\circ} \mathrm{C}$. The dependencies denoted by a, b, c and d correspond to the used external magnetic field of 1500, 3000, 5000 and 10000 Oe, respectively. 


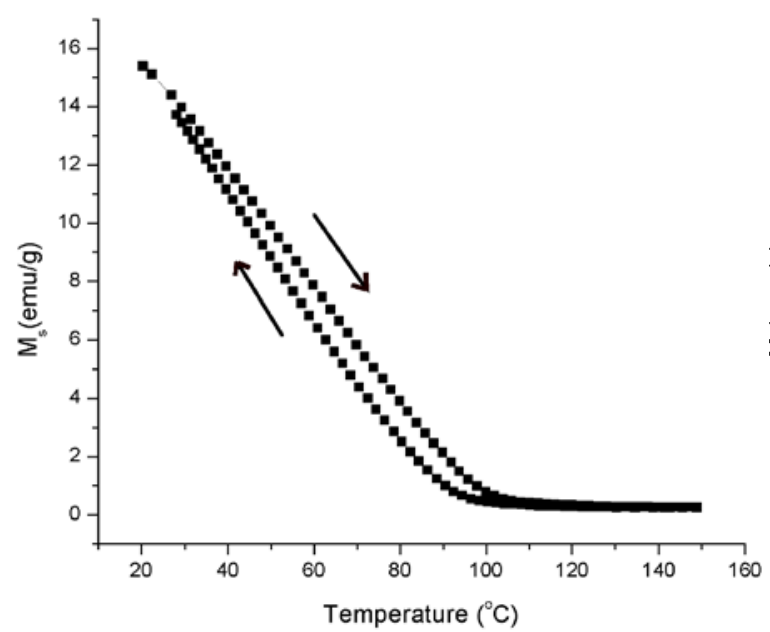

a.)

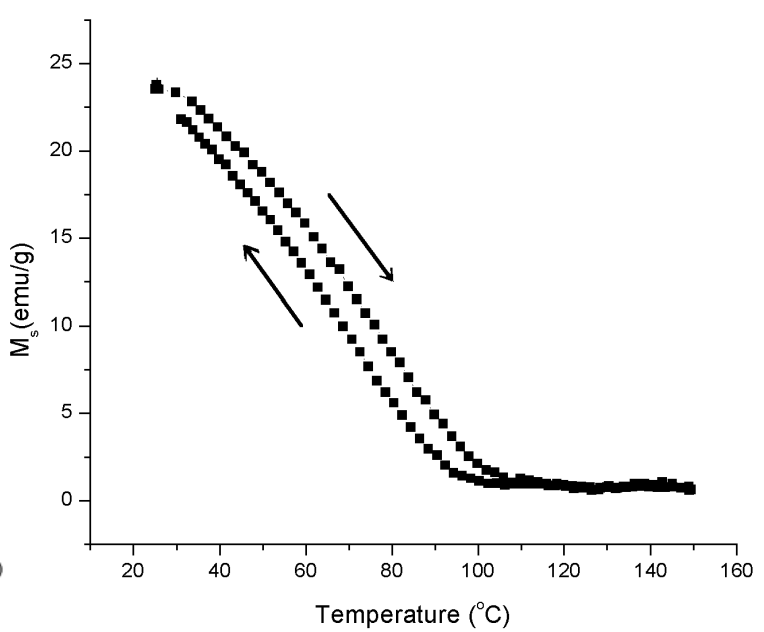

b.)

Fig. 14. Dependence of saturation magnetization on the measurement temperature for the samples synthesized (a) in bulk conditions and calcined at $1100{ }^{\circ} \mathrm{C}$ and (b) in microemulsion and calcined at 1000 ${ }^{\circ} \mathrm{C}$.

The dependencies of saturation magnetization on the measurement temperature towards zero temperature for the sample synthesized in microemulsion and calcined at $1000{ }^{\circ} \mathrm{C}$, under various external fields, are presented in Fig. 13. The blocking temperature (the existence of which implies partly superparamagnetic nature of the synthesized particles), the temperature where field-cooled and zero field-cooled curves divert, decrease with the increase in the intensity of the external magnetic field. A glimpse at the unidentified phase transition, occurring at $37 \mathrm{~K}$, can be catched. Similar saturation magnetization vs. measuring temperature (towards Curie point) dependencies, of the sample synthesized in bulk conditions and calcined at $1100{ }^{\circ} \mathrm{C}$ and of the sample synthesized in microemulsion and calcined at $1000{ }^{\circ} \mathrm{C}$, are presented in Fig. 14. Almost linear decrease in magnetization from room temperature to $90{ }^{\circ} \mathrm{C}$ is noticed in both cases. Curie point was in both cases $\sim 100{ }^{\circ} \mathrm{C}$.

\section{Conclusions}

Two co-precipitation procedures for the synthesis of LaSr-manganite were successfully employed. The one was based on the precipitation of precursor cations in aqueous-ethyl-alcoholic solution by using oxalic acid, and subsequent annealing thereof, whereby the second method was based on the precipitation of precursor cations in reverse micellar domain of CTAB/1-hexanol/water microemulsion, together with subsequent calcination of the obtained precipitate. Whereby in the first, so-called bulk-case $700{ }^{\circ} \mathrm{C}$ was sufficient temperature for obtaining the desired chemical composition, temperatures higher than $1000{ }^{\circ} \mathrm{C}$ ought to be reached in case of the microemulsion-assisted procedure in order to obtain the desired LaSr-manganite product. Studying the chemical pathways leading to the formation of the desired product yielded suggestions that within the bulk procedure, Mn-oxalate transforms to $\mathrm{Mn}_{3} \mathrm{O}_{4}$ that gradually reacts with LaSroxycarbonates to give perovskite manganite, whereas in case of the microemulsionassisted procedure $\mathrm{Mn}_{2} \mathrm{O}_{3}$ and $\mathrm{La}_{2} \mathrm{O}_{2} \mathrm{CO}_{3}$ were detected as the intermediate products with $\mathrm{La}_{2} \mathrm{O}_{2} \mathrm{CO}_{3}$ transforming into $\mathrm{La}_{2} \mathrm{SrO}_{\mathrm{x}}$ which then reacts with $\mathrm{Mn}_{2} \mathrm{O}_{3}$ to give manganite structure. The certain restrictions in the size of co-precipitated particles were detected in 
case of the reverse micellar synthesis as compared to the powders derived from the bulk synthesis. Narrowly dispersed manganite particles in size were detected within the samples co-precipitated in bulk conditions and calcined at $700{ }^{\circ} \mathrm{C}$ for $3 \mathrm{~h}$ and at $1100{ }^{\circ} \mathrm{C}$ for $2 \mathrm{~h}$, as well as within the sample co-precipitated in microemulsion and calcined at $1100{ }^{\circ} \mathrm{C}$. However, the dispersing effects of reverse micelles did not have large influence on the morphological uniformity of the produced powders in comparison with the results obtained by following the co-precipitation procedure in an ordinary aqueous solution. Saturation magnetization increases with the calcination temperature up to values of 45 $\mathrm{emu} / \mathrm{g}$ and $23 \mathrm{emu} / \mathrm{g}$ for the microemulsion-assisted and bulk synthesized samples, calcined at $1100{ }^{\circ} \mathrm{C}$, respectively. Curie point was, comparing the cases of the bulksynthesized sample calcined at $1100^{\circ} \mathrm{C}$ and microemulsion-assisted synthesized sample calcined at $1100{ }^{\circ} \mathrm{C}$, in both cases found at $100{ }^{\circ} \mathrm{C}$. The blocking temperature detected at between $35 \mathrm{~K}$ and $5 \mathrm{~K}$ when the external magnetic field varied from 1500 Oe towards 10000 Oe, suggests partly superparamagnetic nature of the manganite sample, synthesized by performing microemulsion-assisted procedure and calcined at $1000{ }^{\circ} \mathrm{C}$.

\section{References}

1. D. O. Yener, H. Giesche - "Synthesis of Pure and Manganese-, Nickel-, and Zinc-Doped Ferrite Particles in Water-in-Oil Microemulsions”, Journal of the American Ceramic Society 84 (9) 198795 (2001).

2. U. Natarajan, K. Handique, A. Mehra, J. R. Bellare, K. C. Khilar - "Ultrafine Metal Particle Formation in Reverse Micellar Systems: Effects of Intermicellar Exchange on the Formation of Particles”, Langmuir 12, 2670 - 78 (1996).

3. V. Uskoković, M. Drofenik - "Synthesis of Nanocrystalline Nickel-Zinc Ferrites via a Microemulsion Route”, Materials Science Forum 453 - 4, 225 - 30 (2004).

4. M. P. Pileni, T. Zemb, C. Petit - "Solubilization by Reverse Micelles: Solute Localization and Structure Perturbation”, Chemical Physics Letters 118 (4), 414 - 20 (1985).

5. E. E. Carpenter, C. T. Seip, C. J. O'Connor - "Magnetism of Nanophase Metal and Metal Alloy Particles Formed in Ordered Phases”, Journal of Applied Physics 85 (8) 5184 - 6 (1999).

6. C. C. Wang, D. H. Chen, T. C. Huang - "Synthesis of Palladium Nanoparticles in Water-in-Oil Microemulsions”, Colloids and Surfaces A 189, 145 - 154 (2001).

7. J. C. Linehan, J. L. Fulton, R. M. Bean - "Process of Forming Compounds Using Reverse Micelle or Reverse Microemulsion Systems”, US Patent 5,770,172 (1998).

8. M. A. Lopez-Quintela - "Synthesis of Nanomaterials in Microemulsions: Formation Mechanisms and Growth Control”, Current Opinion in Colloid \& Interface Science 8, 137 - 44 (2003).

9. A. Košak, D. Makovec, M. Drofenik - "The Preparation of Spinel Ferrite Nanoparticles Using Precipitation in Water-in-Oil Microemulsions”, Journal of Metastable and Nanocrystalline Materials 23, $251-4$ (2005).

10. X. M. Sui, Y. Chu, S. X. Xing, M. Yu, C. Z. Liu - "Self-Organization of Spherical PANI/TiO 2 Nanocomposites in Reverse Micelles”, Colloids \& Surfaces A 251 (1-3) 103 - 7 (2004).

11. S. Vaucher, M. Li, S. Mann - "Synthesis of Prussian Blue Nanoparticles and Nanocrystal Superlattices in Reverse Microemulsions”, Angewandte Chemie - International Edition 39, 1793 6 (2000).

12. V. Uskoković, M. Drofenik - "Synthesis of Materials within Reverse Micelles”, Surface Review and Letters 12 (5) 2005.

13. R. J. Bell, G. J. Millar, J. Drennan - "Influence of Synthesis Route on the Catalytic Properties of $\mathrm{La}_{1-\mathrm{x}} \mathrm{Sr}_{\mathrm{x}} \mathrm{MnO}_{3}$ ”, Solid State Ionics 131, $211-20$ (2000).

14. A. E. Giannakas, T. C. Vaimakis, A. K. Ladavos, P. N. Trikalitis, P. J. Pomonis - "Variation of Surface Properties and Textural Features of Spinel $\mathrm{ZnAl}_{2} \mathrm{O}_{4}$ and Perovskite $\mathrm{LaMnO}_{3}$ Nanoparticles Prepared via CTAB-Butanol-Octane-Nitrate Salt Microemulsion in the Reverse and Bicontinuous States”, Journal of Colloid and Interface Science 259, 244 - 53 (2003).

15. M. Hayashi, H. Uemura, K. Shimanoe, N. Miura, N. Yamazoe - "Enhanced Electrocatalytic 
Activity for Oxygen Reduction over Carbon-Supported $\mathrm{LaMnO}_{3}$ Prepared by Reverse Micelle Method", Electrochemical and Solid-State Letters 1 (6) 268 - 70 (1998).

16. A. E. Giannakas, A. K. Ladavos, P. J. Pomonis - "Preparation, Characterization and Investigation of Catalytic Activity for NO - CO Reaction of $\mathrm{LaMnO}_{3}$ and $\mathrm{LaFeO}_{3}$ Perovskites Prepared via Microemulsion Method”, Applied Catalysis B 49, 147 - 58 (2004).

17. V. Uskoković, D. Makovec, M. Drofenik - "Synthesis of Lanthanum-Strontium Manganites by a Hydroxide-Precursor Co-Precipitation Method in Solution and Reverse Micellar Microemulsion”, Materials Science Forum 494, 155 - 60 (2005).

18. S. Guillemet-Fritsch, P. Alphonse, Ch. Calmet, H. Coradin, Ph. Tailhades, A. Rousset "Synthesis of $\mathrm{La}_{1-\mathrm{x}} \mathrm{Sr}_{\mathrm{x}} \mathrm{MnO}_{3}$ Powders from Different Precursors", Comptes Rendus Chimie 8 (2) $219-27$ (2005).

19. L. M. Gan, L. H. Zhang, H. S. O. Chan, C. H. Chew, B. H. Loo - "A Novel Method for the Synthesis of Perovskite-Type Mixed Metal Oxides by the Inverse Microemulsion Technique", Journal of Materials Science 31, 1071 - 9 (1996).

20. X. L. Li, J. F. Liu, Y. D. Li - "Low-temperature Conversion Synthesis of $\mathrm{M}(\mathrm{OH})_{2}(\mathrm{M}=\mathrm{Ni}$, Co, Fe) Nanoflakes and Nanorods”, Materials Chemistry and Physics 80, 222 - 7 (2003).

21. M. Gaudon, C. Laberty-Robert, F. Ansart, P. Stevens, A. Rousset - "Preparation and Characterization of $\mathrm{La}_{1-\mathrm{x}} \mathrm{Sr}_{\mathrm{x}} \mathrm{MnO}_{3+\delta}(0 \leq \mathrm{x} \leq 0.6)$ Powder by Sol-Gel Processing”, Solid State Sciences 4, 125 - 133 (2002).

22. Y. H. Huang, Y. G. Xu, C. H. Yan, Z. M. Wang, T. Zhu, C. S. Liao, S. Gao, G. X. Xu - "Soft Chemical Synthesis and Transport Properties of $\mathrm{La}_{0.7} \mathrm{Sr}_{0.3} \mathrm{MnO}_{3}$ Granular Perovskites", Solid State Communications 114, 43 - 47 (2000).

23. B. A. A. Balboul, A. M. El-Roudi, E. Samir, A. G. Othman - "Non-Isothermal Studies of the Decomposition Course of Lanthanum Oxalate Decahydrate", Thermochimica Acta 387, 109 - 114 (2002).

24. E. Knaepen, J. Mullens, J. Yperman, L. C. Van Poucke - "Preparation and Thermal Decomposition of Various Forms of Strontium Oxalate", Thermochimica Acta 284, 213 - 227 (1996).

25. X. Gao, D. Dollimore - "The Thermal Decomposition of Oxalates. Part 26. A Kinetic Study of the Thermal Decomposition of Manganese(II) Oxalate Dihydrate”, Thermochimica Acta 215, 47 - 63 (1993).

26. B. Donkova, D. Mehandjiev - "Mechanism of Decomposition of Manganese(II) Oxalate Dihydrate and Manganese(II) Oxalate Trihydrate”, Thermochimica Acta 421 (1-2), 141 - 9 (2004). 